\title{
Sobre \\ la filmografía mexicana
}

\section{Federico Dávalos Orozco*}

Resumen. El presente ensayo que propone una aproximación critica a las filmografias referidas a la producción cinematográfica mexicana. Las filmografias son, a la vez, uno de los principales productos de la bistoriografia filmica mexicana y una de las principales fuentes de conocimiento sobre nuestro pasado cinematográfico; sin embargo, suelen realizarse sin apegarse a normas metodológicas y técnicas. Se señalan ocho caracteristicas que debe satisfacer una filmografia nacional, referidas a alcance, cantidad de datos, organización y orden de la información, berramientas para el acceso y la recuperación de a la información y automatización, de acuerdo con las recomendaciones de la Federación Internacional de Arcbivos Filmicos (FIAF), Reglas de Catalogación Angloamericanas, ISBN (NBM) y MARC II. A partir de los parámetros anteriores, se evaluan nueve filmografias sobre el cine mexicano publicadas entre 1969 y 2001.

\section{Introducción}

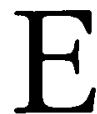
$s$ a partir de las insuficiencias de un trabajo anterior (Dávalos, 1989) sobre los proble mas de la filmografía, que este ensayo reelaboró y actualizó una aproximación crítica a los trabajos filmográficos referidos a la producción cinematográfica mexicana.

Entre las fuentes secundarias para el estudio de la cinematografía se encuentran las fuentes historiográficas (Dávalos, 1989: 111). Es dentro de

- Especialista en sociología del cine mexicano. Técnico titular "A" T.C., adscrito a la Coordinación de Ciencias de la Comunicación de la Facultad de Ciencias Políticas y Sociales de la UNAM. Correo electrónico: fdavalos@servidor.unam.mx 
esta categoría que podemos ubicar a los diversos repertorios filmográficos sobre el cine nacional.

Las filmografías son, a la vez, uno de los principales productos de la historiografia filmica mexicana y una de las principales fuentes de conocimiento sobre nuestro pasado cinematográfico.

Los trabajos filmográficos son indispensables por dos razones principales:

1. Por la desaparición física de prácticamente $90 \%$ de la produçción cinematográfica anterior a 1931 y por la dificultad para acceder a las producciones sonoras. Debemos agregar las catástrofes que han aniquilado colecciones, archivos y filmotecas. Las filmografías contribuyen a la recuperación de datos sobre la producción o dejan constancia de la existencia de obras perdidas.

2. Por la ausencia de catálogos de producción sistemáticos y confiables que nos orienten o informen acerca de los títulos filmados, sus realizadores, productores, intérpretes, su extensión, géneros y asuntos abordados. Éste ha sido un problema persistente desde los orígenes del cinematógrafo hasta la actualidad.

La ausencia de registros ha obligado, tanto a las viejas generaciones de investigadores como a las nuevas, a la elaboración de repertorios filmográficos que han sustentado sus ensayos, trabajos históricos o críticos. Sin desconocer el titánico esfuerzo de esas filmografias para indagar, precisar y acotar el mapa cinematográfico del país, sin menospreciar las ambiciones totalizadoras de muchos de ellos, debemos señalar que, a nuestro juicio, en todos los casos se presentan insuficiencias metodológicas y técnicas.

El trabajo filmográfico debe establecerse sobre bases metodológicas y técnicas fundadas en normas de alcance nacional e internacional. Esta necesidad ya la advirtió, desde los años sesenta, la bibliotecóloga y filmógrafa María Isabel de la Fuente ( $c f$. De la Fuente, 1965-1967: i-vi).

Un trabajo de naturaleza filmográfica debe satisfacer por lo menos las siguientes características:

1. Incorporar todas las producciones nacionales, sin considerar género o duración.

2. Ordenar el material cronológicamente atendiendo a su fecha de producción. Sólo emplear de manera auxiliar para fechar las cintas otros criterios (fecha de exhibición o de localización).

La ficha filmográfica debe ser completa y exhaustiva. La ficha técnica debe considerar todo el elenco técnico y artístico conocido; la sinopsis, de preferencia, debe reproducir totalmente los documentos originales e incorporar, además, en la medida de lo posible, fechas de filmación, lugares de filmación, fecha de estreno, cines de estreno, así como notas y 
comentarios que informen o aclaren las circunstancias de filmación y exhibición de la cinta en cuestión, o que apunten observaciones sobre los datos contenidos en la misma ficha.

Es decir, cada ficha filmográfica debe ser del tercer nivel de acuerdo con las recomendaciones de las Reglas de catalogación angloamericanas, $2^{2}$ ed., rev. 1988, o del segundo nivel de acuerdo con las normas que la Comisión de Catalogación, Clasificación y Conservación de la Red Universitaria de Televisión y Video asienta en su Guía para la catalogación descriptiva de materiales audiovisuales (RUTV-CCCC, 1993).

De acuerdo con la Federación Internacional de Archivos Fílmicos (FIAF) es indispensable que toda filmografa se fundamente en fuentes primarias, es decir que parta de la revisión de la película misma, que es la fuente primaria ( $c f$. FIAF, 1982: 8-9). En su caso, debe incorporar, de alguna forma, la relación de las fuentes secundarias de cada uno de los datos que conforman cada una de las fictras filmográficas. La carencia de este aparato crítico demerita todos tos ésfuerzos que se realicen en la materia y dificulta la evaluación de las aportaciones realizadas ( $c f$. FIAF, 1982: 8-9).

3. Conforme a las recomendaciones de la FIAF, debe darse total preferencia al registro de producciones nacionales que hayan sido terminadas, se hayan o no exhibido comercialmente. En caso de considerar la pertinencia de registrar proyectos, películas inconclusas, casos dudosos o cintas no pacionales, por cualquier razón, deberán agruparse independientemente del resto del repertorio fílmico, siguiendo criterios definidos explícitamente.

4. Una parte fundamental de toda filmografía será la elaboración de índices de películas, onomásticos (nombres, seudónimos, sobrenombres) y corporativos y demás que faciliten la consulta del trabajo.

5. Cada película deberá tener una clave o número de identificación.

6. Los elementos de la ficha filmográfica deberán presentarse en el orden y con la puntuación y sintaxis prescritas por la RCA2 por la norma International Standard Bibliographic Description for Non-Book Materials, ISBD (NBM) o por los trabajos derivados de éstos, como Archival moving image material: a cataloging manual, de Wendy White-Hensen, (Hensen, 1984) editado por la Biblioteca del Congreso de los Estados Unidos; The FIAF cataloguing rules for film archives, compilado y editado por Harriet W. Harrison para la Comisión de Catalogación de la FiAf en 1991 y traducido recientemente al español en una edición publicada por la Filmoteca de la UNAM (Harrison, 1991, 1998) y la Guía para la catalogación descriptiva de materiales audiovisuales, publicada por la Red Universitaria de Televisión y Video en 1993 (RUTV-CCCC, 1993).

7. En caso de automatizarse, la información, la estructura de las bases de datos, así como las características de cada uno de los registros que las formen y de la definición de los campos, deberá elaborarse siguiendo las recomendaciones del formato MARC I de la Biblioteca del Congreso de los 
Estados Unidos o del formato CCF (Common Communication Format), de la ONU.

Consideramos que, siguiendo estas sencillas recomendaciones, la filmografía del cine mexicano cumplirá cabalmente con su función de informar y registrar la producción cinematográfica. En la actualidad, esta necesidad es una obligación urgente. Nuestro cine carece de catálogos de producción.

\section{Las filmografias del cine mexicano.}

Los trabajos filmográficos en sentido estricto sobre el cine mexicano editados hasta el momento son: los de Dávalos Orozco y Vázquez Bernal (1981-1982 y 1985); el coordinado por Emilio García Riera (1986); los elaborados por Aurelio de los Reyes (1981, 19861994 y 2000); el trabajo recepcional de Dávalos Orozco (1989); el apéndice filmográfico de Ramírez (1989); los trabajos filmográficos del equipo que encabeza Juan Felipe Leal: Jablonska y Leal (1991), Leal, Barraza y Jablonska (1993), Leal, Barraza y Flores Villela (1994); el monumental y sintético esfuerzo de Viñas (1992); y las dos ediciones de la Historia documental del cine mexicano de Emilio García Riera (1969-1978; 1992-1996) que culminan y amplían esfuerzos previos por establecer la filmografía sonora mexicana. A los anteriores debemos agregar Cien años de cine mexicano (1999) editado en CD-ROM y el sistema de consulta en línea Filmografía mexicana de la Filmoteca de la UNAM. Pueden considerarse de "exploración filmográfica" o de "filmografias narrativas" las obras de Gabriel Ramírez (1980) sobre el cine yucateco y la de Guillermo Vaidovits (1987 y 1989) sobre el cine tapatío. Existen también otros trabajos de alcance limitado que no comentaremos aquí.

Todos los trabajos mencionados poseen virtudes y fallas; es necesario desarrollar y ampliar las primeras y evitar las segundas.

1. Federico Dávalos Orozco y Esperanza Vázquez Bernal publicaron en 1985 Filmografia general del cine mexicano. (1906-1931), versión corregida y ampliada del trabajo editado en forma mimeografiada en 1981-1982.

Dávalos y Vázquez se proponen inventariar la producción fílmica mexicana del periodo mudo y de transición al sonoro con una duración mayor de 40 minutos y tienen como fuente principal la prensa y los trabajos historiográficos entonces disponibles. La filmografía sigue, en la medida de lo posible, el orden cronológico de su producción; cada título va acompañado, en caso de que se conozca, de su ficha técnica, de una sinopsis y de notas y comentarios. Se registran las producciones mexicanas, realizadas en el país o en el extranjero; incluye sólo cintas 
terminadas, se hayan estrenado o no; excluye el registro de proyectos de filmación. Las fuentes y referencias para el establecimiento de las fichas aparece enlistado de manera general en una bibliografía al final de la obra. Como herramienta auxiliar, el libro dispone de un índice de directores y de títulos.

Nuestras observaciones generales a este trabajo son las siguientes:

a) Limitar el registro a las cintas con una duración superior a los 40 minutos es una grave limitante para una filmografía de un periodo tan poco conocido. Refleja una extrapolación retrógada del interés generalizado por la industria cinematográfica de sólo considerar existentes los largometrajes y menospreciar los cortometrajes y las revistas noticiosas. Es fundamental considerar en una filmografía, especialmente del cine silente, todo tipo de producciones de cualquier longitud.

b) El uso de las fuentes puede considerarse adecuado y sistemático; sin embargo, al no aparecer integradas en las fichas las fuentes de donde proviene la información, no poseemos manera de verificar directa e inmediatamente la validez de la información proporcionada.

c) La ordenación cronológica de la filmografía de acuerdo a su fecha de producción es un requisito indispensable y fundamental en toda filmografía. Sólo cuando sea imposible saber o inferir ésta deberemos recurrir a otras formas de datación (fecha de primera exhibición conocida o fecha de la primera noticia conocida sobre la cinta en cuestión), pero teniendo siempre en mente la necesidad de definir y establecer su fecha posible de filmación.

d) En cuanto a la ficha filmográfica, consideramos que en lo general es correcta. Falta incluir la fecha y los cines de estrenúm. En el caso de sinopsis es observable que, aunque los autores intentan apegar su redacción al espíritu de las fuentes, lo ideal sería reproducir o transcribir el texto de las fuentes originales en los casos en los que la película sea inaccesible o haya desaparecido. Las notas y comentarios son pertinentes en la medida en que ayudan a ubicar, comprender y analizar las circunstancias de filmación, distribución y exhibición de la cinta respectiva y, en su caso, compensan la ausencia de datos ciertos sobre sus creadores o sobre su argumento.

e) Conforme a las recomendaciones de la FIAF, la filmografía da preferencia a las producciones nacionales. Otros criterios, por ejemplo, incorporar producciones extranjeras, dirigidas o actuadas por mexicanos, no es indispensable; incluir proyectos o títulos cuya producción es dudosa podría generar confusiones entre los lectores.

$f$ En un trabajo de esta naturaleza los índices son fundamentales. En el presente caso no debería limitarse a los directores, sino extenderse a todas las personas que intervienen en la realización del filme. 
2. La Cineteca Nacional editó en 1986 Filmografía mexicana de medio y largometrajes, 1906-1940, elaborada bajo la coordinación de Emilio García Riera, con la participación de Luis Gerardo Jaramillo Herrera y Siboney Obscura Gutiérrez, y el apoyo de los demás miembros de la Oficina de Análisis e Investigación de la Cineteca Nacional. Esta obra es un ejemplo de como No debe realizarse un trabajo filmográfico, por lo siguiente:

a) No parte de una investigación original sobre las fuentes, factor que consideramos indispensable para la elaboración de una filmografía. Sólo el estudio crítico de las fuentes secundarias disponibles y la comprensión del periodo permitiría a los autores deducir conclusiones sobre la filmografía. En vez de lo anterior, García Riera y sus colaboradores optan por el camino fácil de elaborar una especie de "sincretismo filmográfico" o "empastelado filmográfico" integrando y sumando acríticamente elementos provenientes fundamentalmente de la primera versión de la filmografía de Dávalos y Vázquez (1981-1982), complementando datos con una versión inédita de la que Aurelio de los Reyes publica en 1986.

b) El trabajo de la Cineteca Nacional y García Riera reproduce fichas del periodo silente del trabajo de Dávalos y Vázquez comentado más arriba. Al hacerlo, se cometen imperdonables errores de transcripción y tergiversación del original, añadiendo datos dudosos, alterando información e incurriendo en omisiones lamentables. Entre otras cosas, alteran títulos, cambian datos de la ficha técnica o de la sinopsis tergiversando el sentido original de la información.

c) En todos los casos, la edición de la Cineteca Nacional, contraviniendo las recomendaciones de la FIAF reduce arbitrariamente los créditos proporcionados a una breve lista que ellos, subjetivamente, consideran fundamentales. Así, no aparecen los créditos de "edición", la fecha de filmación, etc. También, eliminan sin explicación el crédito de "dirección artística", "dirección escénica" o "dirección técnica" y lo sustituyen por el más impreciso y general de "dirección".

d) Dicha filmografía incorpora alrededor de 30 nuevas fichas filmográficas del periodo 1906-1929, de las cuales dos terceras partes son meras presunciones derivadas de la ignorancia y fruto de la falta de investigación en las fuentes. Así, adiciona y presenta como "inconclusos" meros proyectos que jamás se realizaron, agrega indebidamente - cintas inconclusas, incorpora como largometrajes cintas cortas e incluye producciónes extranjeras dirigidas por mexicanos, etcétera.

e) La edición de la Cineteca Nacional y de García Riera copia incluso erratas o errores a pesar de haber sido aclarados expresamente en una fe de erratas y correcciones por Dávalos y Vázquez. 
f) La edición coordinada por García Riera y publicada por la Cineteca Nacional tiene, entre el cúmulo de fallas, dos virtudes marginales: cuando agrega fichas de cintas inconclusas o de producciones extranjeras dirigidas por nacionales, las separa del resto; y sus índices onomásticos, corporativos y de títulos, que agrupan alfabéticamente todos los nombres de personas e institucionales que se mencionan en el texto.

Consideramos que la Filmografia mexicana de medio y largometrajes 1906-1940, ha provocado un grave daño a la investigación histórica del cine mexicanúm. Es imperdonable que la Cineteca Nacional haya respaldado la reproducción y publicación por parte de Emilio García Riera y sus colaboradores de un trabajo previamente editado y difundido. No puede avanzarse en la reconstrucción de nuestro pasado filmico si un grupo de personas con pocos escrúpulos académicos, avalados por una institución oficial como la Cineteca Nacional, se dedican a destruir metódicamente la paciente y ardua tarea de establecer las fichas filmográficas, especialmente cuando se refieren a periodos que carecen de registros o cuya producción fílmica está perdida.

Al añadir al original un cúmulo acrítico de datos provenientes de las más diversas fuentes sólo generan un trabajo confuso, carente de validez real y de sustento sólido. La ignorancia, la premura, la improvisación, la prepotencia y la ausencia de una verdadera investigación saltan a la vista de cualquiera mínimamente interesado en el estudio de nuestro pasado filmico. Nos preocupa sobremanera la desorientación que en el público lector y en los estudiosos puede producir un trabajo que no satisface siquiera los lineamientos de una mediana tarea escolar. Los efectos nefastos de la labor desinformadora cometida por Emilio García Riera y sus colaboradores y difundida por la Cineteca Nacional sólo podrán evaluarse cabalmente cuando, con el paso del tiempo, algunos aquí o en el extranjero, desprevenidamente, lo tomen como fuente fidedigna de datos filmográficos.

3. La Filmografía del cine mudo mexicano, 1896-1930 (tres volúmenes publicados en 1986, 1994 y 2000), importante trabajo de Aurelio de los Reyes, es el repertorio sistematizado de toda la producción fílmica mexicana localizada por el autor desde la llegada de los empleados de los Lumière en agosto de 1896, hasta 1930. Allí vacía toda la información filmográfica que sólo de manera tangencial o parcial toca en su obra Cine y sociedad en México 1896-1930, del que se han publicado dos de los tres volúmenes proyectados: Vivir de sueños, vol. I (1896-1920) (De los Reyes, 1983a) y Bajo el cielo de México, vol. II (1920-1924) (De los Reyes, 1988). Como ya lo hemos indicado en otras partes, dicho trabajo recurre a todas las fuentes primarias y secundarias a su alcance. De los Reyes 
ordena su material cronológicamente atendiendo a la fecha de exhibición o de localización de la información. Sólo registra producciones nacionales, a excepción de las filmadas por los enviados de los Lumière a nuestro país. En el caso de los documentales, el autor reproduce -cuando cuenta con ella- toda la información sobre su contenido; en el caso de las cintas de argumento no proporciona sinopsis. Las fichas técnicas, en lo general, contienen sólo la información básica. Incluye en su relación proyectos y cintas inconclusas. El trabajo nos remite a su obra principal para la consulta de sus fuentes y para ampliar comentarios sobre las cintas.

Para Aurelio de los Reyes, su catálogo filmográfico es auxiliar y un subproducto de su investigación principal. Ésta, como su nombre lo indica, es el análisis del impacto social del cine en nuestro país. En ese sentido, no orienta sus esfuerzos al acopio sistemático de información filmográfica, aunque, por razones obvias, la localización, identificación de cintas, así como el establecimiento de créditos filmográficos ocupan una parte considerable de su trabajo.

De ese modo, la tarea de recuperación de todo el periodo anterior a 1917 es notable y fundamental para la comprensión de la historia del cine mexicano al que coloca como un ejemplo peculiar dentro del contexto cinematográfico mundial. No podemos decir lo mismo de los títulos registrados correspondientes al periodo argumental. La pobreza de la información sobre este periodo en el primer volumen que abarca hasta 1920 contrasta con la riqueza de su monumental trabajo complementario. Sin embargo, en los dos últimos volúmenes se muestra más acucioso en el registro de la información filmográfica del cine de argumento.

Las siguientes son nuestras observaciones generales a la filmografía de De los Reyes:

a) Correctamente, no discrimina las cintas en razón de su longitud o género, por lo que incluye corto, medio y largometrajes, así como revistas y noticieros fílmicos.

b) El uso de las fuentes es adecuado, pero, en primer lugar, nos remite a otra obra para su consulta; y, en segundo, insistimos en la necesidad de que para el caso del cine mudo, éstas aparezcan en cada ficha filmográfica para permitir una evaluación crítica de la información proporcionada.

c) Nos parece cuestionable la ordenación del material conforme a las fechas de exhibición o localización. Este criterio sólo debe ser auxiliar y emplearse exclusivamente cuando no estemos en posibilidad de fechar su producción.

d) La ficha filmográfica no es exhaustiva ni sistemática. Una filmografía de esa naturaleza debería proporcionar al estudioso todos los datos disponibles. En cambio, el autor nos informa con amplitud del 
contenido de las cintas documentales, no temiendo la longitud de los documentos citados. No entendemos por que no hizo lo mismo en las películas argumentales. Las notas y comentarios, aunque parcos, pueden considerarse lo suficientemente aclaratorios.

$e$ ) Incluye proyectos de filmación y filmes inconclusos. Aunque no siempre hace la observación pertinente, consideramos que siempre, en estos casos, debería hacerse una relación a parte o distinguirse expresamente, para evitar confusiones.

$f)$ Se echa de menos un indispensabilísimo índice onomástico y filmico. Su ausencia dificulta la consulta de la obra. Los índices son indispensables en todo trabajo filmográfico.

4. Como apéndice de Crónica del cine mudo mexicano, Gabriel Ramírez publica en 1989 una "Filmografía de medio y largometraje de ficción" (Ramírez, 1989: 255-279).

Como su título lo indica, el autor relaciona las cintas de argumento con una duración mayor a los 40 minutos (1916-1931). Sus fuentes informativas son sus propias indagaciones en la prensa y las obras historiográficas y filmográficas anteriores. La filmografía se ordena en forma cronológica y se proporciona la ficha técnica, fecha y salas de estreno de cada cinta. Tratándose de un trabajo complementario, omite las sinopsis que se desarrollan ampliamente en el cuerpo del texto, con las anotaciones y los comentarios pertinentes. Registra todas las producciones de mexicanos terminadas o inconclusas realizadas en México o en el extranjero. Indica sus fuentes de manera general al inicio de la filmografía. Como auxiliar para la recuperación de información, la obra incluye un índice onomástico y de títulos.

Nuestras observaciones generales sobre la filmografía de Gabriel Ramírez, son las siguientes:

a) Reitera el equívoco de considerar de interés sólo los medio o largometrajes de ficción, marginando, de esta manera, una buena parte de la producción mexicana del periodo mudo. Las producciones mexicanas realizadas en el extranjero se disciernen con dificultad. Las inconclusas se indican de manera expresa.

b) Aunque señala sus fuentes al inicio, éstas no se encuentran integradas a cada una de las fichas, impidiendo la confrontación directa de la información proporcionada. No son discernibles sus aportaciones sobre las de otras fuentes.

c) Es correcta la ordenación cronológica de los títulos y la información de la ficha técnica es exhaustiva, como es habitual en la obra del autor. Las sinopsis, aunque ausentes en este recuento, son expuestas con amplias citas provenientes de fuentes secundarias en el corpus principal del libro. 
d) El índice onomástico y de películas es muy completo. Permite relacionar la información de la filmografía con la del resto del texto. Incluye todos los nombres de personas, pero carece de índice corporativo.

5. En 1992 se publica el Indice cronológico del cine mexicano 18961992 de Moisés Viñas. Es una gbra utilísima por su extensión y por su carácter manual.

Se trata de un repertorio cronológico-alfabético de toda la producción fílmica mexicana desde la llegada de los empleados de Lumière al país hasta el año de 1992. En la actualidad se prepara una edición revisada y actualizada. Su fuente principal son trabajos historiográficos, filmográficos y monográficos. Para el establecimiento de la filmografía de los años recientes, se fundamenta en la prensa $y$, probablemente, en algunas de las películas mismas. La filmografía se presenta en capítulos anuales y, dentro de éstos, las cintas aparecen en orden alfabético de título. Cada asiento incluye de manera sintética ficha técnica, excluyendo algunos datos. Es notable el esfuerzo por incorporar elementos para el análisis formal y temático de las cintas ("género formal", "género dramático"), aunque carece de sinopsis. La obra considera el registro de cintas extranjeras que han sido dirigidas por mexicanos o por extranjeros afincados en México; también, se observa la inclusión de producciones videograbadas, aunque en ambos casos no se establecen con claridad los criterios de selección. El trabajo propone como herramienta de consulta un índice de títulos que nos remite al año de producción, un índice de series y otro de películas de episodios y cuentos con envíos a las películas que las integran, y una lista de compañias productoras. Carece de índices onomásticos y corporativos.

Nuestras observaciones generales a este trabajo son las siguientes:

a) Es un acierto la presentación manual de este repertorio casi total. Desafortunadamente, la carencia de índices onomásticos y corporativos y la doble búsqueda a que nos obliga el índice de títulos, desvirtúa el trabajo.

b) Es correcta la inclusión de todo tipo de producciones fílmicas en el repertorio sin considerar su longitud.

c) No establece los criterios y normas para recopilar producciones extranjeras. Tampoco es claro en los criterios que permiten la inclusión de producciones en videotape. En este caso, no sabemos si se trata de videos producidos por realizadores de cine, de videos producidos por los miembros de los sindicatos cinematográficos (videobomes) o, simplemente, la incorporación arbitraria de programas o series unitarios para la televisión.

d) Es muy importante la inclusión en la ficha técnica de lo que el 
autor llama "género formal" y "género dramático" que ya habían sido propuestos -en otros términos- por un trabajo anterior de Dávalos Orozco (1989). Estos datos dan pie para un estudio de carácter informétrico de forma y contenido.

e) Como en otros casos, podemos suponer que el autor usa las fuentes en forma adecuada y sistemática; sin embargo; al no aparecer integradas en las fichas, es difícil verificar directa e inmediatamente la validez de los datos. Es imposible verificar títulos mencionados sólo por este autor o datos que difieren de los proporcionados por otras fuentes. Esto origina incertidumbre. No puede saberse cuándo se trata de una aportación del autor o cuándo se trata de un error o de una interpretación válida de las fuentes.

f) La ordenación cronológica de la filmografía de acuerdo a su fecha de producción es un requisito indispensable y fundamental en toda filmografia. Viñas satisface a medias este principio, pues arregla alfabéticamente las cintas dentro de cada año.

g) En un trabajo de esta naturaleza los índices son fundamentales. En el presente caso, no debería limitarse a los títulos, sino extenderse a todas las personas que intervienen en la realización del filme. Igualmente, se requiere una forma más ágil de consultar la información. Los índices deben permitir un acceso directo a las películas con el uso de páginas o número de cinta.

6. El equipo que encabeza Juan Felipe Leal, ha publicado hasta la fecha los siguientes trabajos filmográficos: La Revolución mexicana en el cine nacional: filmografia 1911-1917 (1991) de Alejandra Jablonska y Leal, Vistas que no se ven: filmografia mexicana 1896-1910 (1993) de Leal, Eduardo Barraza y Jablonska; y $E l$ arcón de las vistas: Cartelera cinematográfica del cine en México 1896-1910 (1994) de Leal, Barraza y Arturo Flores Villela.

El interés de Leal y asociados sigue dos direcciones. Primero, se interesan por el estudio de la forma en la que la cinematografía nacional registra y reproduce los dramáticos acontecimientos de la Revolución mexicana; más tarde, se proponen una revisión y sistematización de los datos filmográficos correspondientes al periodo primitivo de nuestro cine anterior a 1910. Así, en sus obras, registran toda la producción fílmica mexicana desde el arribo de Gabriel Veyre y Claude Ferdinand Bon Bernard a la capital mexicana en agosto de 1896, hasta 1917, fecha que cierra simbólicamente el ciclo de la guerra revolucionaria con la promulgación, el 5 de febrero, de la nueva Constitución Política de la República. Su fuente principal es la información hemerográfica y los trabajos historiográficos disponibles. Las filmografías siguen, en la medida de lo posible, el orden cronológico de su producción; cada título va acompañado, en caso de que se conozca, de su ficha técnica, de una 
sinopsis, de notas, comentarios y testimonios. Se registran las producciones mexicanas, realizadas en el país. La precariedad de las fuentes no siempre permite dilucidar si las cintas fueron terminadas, si fueron exhibidas o si quedaron en meros proyectos de filmación, pero cuando existe, se proporciona toda la información disponible. Las obras de este equipo de investigadores son -después de la propuesta de Dávalos en 1989las primeras en presentar las fuentes y referencias para el establecimiento de las fichas en cada uno de los registros, lo que significa un enorme adelanto. Como herramienta auxiliar, las obras disponen de índices onomásticos y de títulos.

Nuestras observaciones generales a los trabajos publicados por Leal, Jablonska, Barraza y Flores son las siguientes:

a) De acuerdo con las recomendaciones de la FIAF, no discriminan material fílmico en función de su extensión. De manera natural y sin hacer consideraciones al respecto, registran todo tipo de producciones.

b) El uso de las fuentes es adecuado y sistemático. Al integrarse en cada una de las fichas las fuentes documentales de la información consignada, los autores proporcionan a los estudiosos un recurso fundamental para verificar directa e inmediatamente la validez y la calidad de la información proporcionada, las fuentes consultadas o las fuentes disponibles para cada título.

c) Atiende la necesaria ordenación cronológica de la filmografía de acuerdo a su fecha de producción. Cuando eso no es posible, sin perder de vista este criterio primordial, recurre a otras formas de datación, como la fecha de primera exhibición conocida o fecha de la primera noticia conocida sobre la cinta en cuestión.

d) En cuanto a la ficha filmográfica, consideramos que en lo general es correcta. Por la naturaleza de las fuentes y de la producción primitiva enfatiza y caracteriza cierto tipo de datos, como en el rubro de exhibición donde se recogen, además de las salas de estreno, las empresas exhibidoras.

e) Por tratarse de películas en su mayor parte perdidas, las sinopsis, cuando existen, reproducen textos o testimonios originales. Igualmente, las notas y comentarios incluyen testimonios que ayudan a contextualizar las circunstancias de filmación, distribución y exhibición de la cinta y, en ocasiones, compensan la ausencia de datos ciertos sobre sus creadores o sobre su argumento.

7. Sin duda, la obra más conocida de este conjunto es la monumental Historia documental del cine mexicano de Emilio García Riera que a la fecha lleva dos ediciones: 1969-1978 y 1992-1996. Puede considerarse que es la culminación de una serie de esfuerzos filmográficos sobre el periodo 
sonoro, como las presentadas en los anuarios de Cine Gráfico (1938?1947?), la Guía oficial del cine en México (1943-1944), Anuario cinematográfico latinoamericano (1947), la contenida en la obra de Ricardo Rangel y Rafael E. Portas (1957), la de María Isabel de la Fuente (19651967) y la de los anuarios cinematográficos publicados por la Dirección General de Cinematografía de 1970 a 1977.

García Riera elabora un inventario de la producción fílmica mexicana sonora de largometraje. En la primera edición de la Historia documental... llega hasta el año de 1965 y en la segunda hasta 1976. Sus fuentes son la prensa, los trabajos historiográficos disponibles, testimonios, el acceso a fuentes primarias, así como notas, apuntes y recuerdos. La filmografía sigue, en la medida de lo posible un estricto orden cronológico de acuerdo con la fecha de poducción de las cintas; cada título va acompañado de su ficha técnica, de una sinopsis y de notas y comentarios. Registra las producciones mexicanas y coproducciones de participación mexicana realizadas en el país o en el extranjero; incluye sólo cintas terminadas. El material se encuentra organizado en capítulos anuales, cada uno de los cuales presenta un panorama de la situación del cine durante el periodo. Al final de cada año, incluye notas acerca de la producción de cortometrajes, sobre la participación de mexicanos en películas extranjeras, de extranjeros que filman en territorio nacional y sobre la producción cinematográfica de los países de habla española. Las fuentes y referencias para el establecimiento de las fichas aparece enlistado de manera general en una bibliografía al final de la obra, aunque cuando inserta citas o documentos señala de manera inmediata la fuente. Como herramienta auxiliar, la obra dispone de un indice de personas y de títulos de película.

Nuestras observaciones generales a este trabajo son las siguientes:

a) Limita el registro filmográfico a las cintas de largometraje. Los medio y cortometrajes, como las revistas noticiosas son considerados de carácter secundario $\mathrm{y}$, por lo tanto, relegados al apéndice de cada año. Esto es una limitante para una filmografía nacional.

b) El uso de las fuentes puede considerarse adecuado y sistemático; sin embargo, al no aparecer integradas en las fichas las referencias, no puede verificarse la validez de la información proporcionada. Esto es notable al comparar las dos ediciones. Podemos suponer que en la segunda edición muchas de las fichas fueron cotejadas con las fuentes primarias, pero en ningún momento se nos informa que los datos provienen de los créditos en pantalla o de fuentes secundarias. La misma segunda edición viene acompañada de un tomo, el número 18 , con correcciones de fondo a numerosas fichas filmográficas, que acentúa la incertidumbre sobre las fuentes de las fichas filmográficas. Por otra parte, no distingue en las fichas aque- 
llos datos provenientes de las diversas fuentes de las interpolaciones hechas por el autor.

c) García Riera es muy riguroso en la ordenación cronológica de la filmografia de acuerdo con su fecha de producción.

d) En cuanto a la ficha filmográfica, tiende a ser exhaustiva. Además de los datos técnicos, incluye fechas y estudios de rodaje, locaciones, costo de producción, fechas y cines de estreno y datos sobre la clasificación y el número de autorización otorgado por la Dirección General de Cinematografía.

Podemos suponer, aunque no es explícito, que la elaboración de las sinopsis se basa en las fuentes primarias. Cuando éstas no están disponibles, cita las fuentes secundarias en las que se apoya.

Las notas complementarias son muy completas. García Riera las divide básicamente en comentarios y testimonios; en los primeros, hace precisiones sobre la ficha técnica y el elenco, glosa las incidencias de la cinta y hace una valoración crítica de la película. En los testimonios, incorpora observaciones y comentarios de la época o de otros críticos. Desfortunada y lamentablemente, los testimonios han sido reducidos al mínimo en la segunda edición de la Historia documental..., disminuyendo gravemente su carácter "documental".

e) La obra incluye índices onomástico y filmográfico. En la primera edición aparecen en cada uno de los nueve volúmenes; en la segunda edición, tales índices se publican en el último tomo, con las correcciones; incluye en el índice onomástico lugar y fecha de nacimiento y muerte de las personas enlistadas. Sin embargo, estas herramientas fundamentales carecen de un índice corporativo.

8. Los últimos trabajos que analizaremos aquí son el documento electrónico Cien años de cine mexicano 1896-1996, editado en CD-ROM por CONACULTA e IMCINE en 1999, cuya elaboración fue coordinada por Fernando Martinez Ruiz y Ricardo Reynoso Serralde y el sistema de consulta en línea Filmografía mexicana desarrollado por la Dirección General de Actividades Cinematográficas de la UNAM y que se encuentra disponible en internet en la dirección http://www.unam.mx/Filmoteca. Ambos trabajos tienen la característica de apoyarse en la herramienta informática para la construcción de una filmografía mexicana, pero ninguno aplica las normas del formato MARC II o del formato CCF.

El primero, Cien años de cine mexicano 1896-1996, es un ambicioso proyecto. Además de ser una base de datos filmográfica total sobre el cine mexicano, presenta varios ensayos monográficos sobre su desarrollo histórico y una base de datos biográfica de personalidades selectas de la industria.

La base de datos filmográfica incluye corto, medio y largometrajes del periodo mudo y los largometrajes producidos durante el periodo sonoro 
hasta 1996. Aunque incluye una amplia bibliografía, las fuentes de la información fílmica no son explícitas, pero podemos suponer que son los trabajos filmográficos de García Riera, de De los Reyes y de Viñas, complementados con la información proporcionada por las instituciones patrocinadoras. Cada título va acompañado de su ficha técnica y de una sinopsis. A pesar de ser una base de datos, su sistema de consulta es totalmente disfuncional. Como herramienta auxiliar es muy limitada. Esta obra es un claro ejemplo de que por sí misma la computación no resuelve los problemas de organización y recuperación de la información y que genera nuevos problemas. Como en el trabajo de Viñas, el esfuerzo de reunir en una sola obra manuable toda la producción nacional se ve disminuido por la inhabilidad de elaborar una herramienta de consulta adecuada. No es posible realizar búsquedas con lógica booleana o de caracteres truncados o por palabras sueltas o por texto libre. Es esencial conocer exactamente el título de una obra para poder recuperar sus datos; es necesario conocer el nombre de pila de una persona para recuperar información acerca de ella, o conocer exactamente el título de una obra para poder localizarla. Esto contradice las normas más elementales de las obras de consulta y deja en ridículo el enorme poder de las computadoras que se desperdicia absurdamente en un producto bien intencionado, pero pésimamente realizado. En este caso, no es posible aplicar el criterio cronólogico ni revisar secuencialmente la base de datos. Mucha información disponible se pierde por ser irrecuperable.

Esta base de datos no registra cortos ni mediometrajes, noticieros y revistas del periodo sonoro. No señala de manera explícita las fuentes para el establecimiento de las fichas filmográficas; los datos que contiene son minimos y carecen de notas y comentarios. En las breves caracterizaciones de las cintas tampoco se apuntan las fuentes.

La máquina de búsqueda tiene un gravísimo defecto derivado de su diseño: cuando la ficha de una cinta con pocos datos tiene campos vacíos, el sistema la presenta rellenando esos campos con los datos de fichas o registros adyacentes. Esta terrible falla permite que el sistema invente a placer fichas y datos que producen una confusión indebida $e$ indeseable.

Por lo anterior, debemos cuestionar severamente las herramientas de recuperación provistos en este $\mathrm{CD}$-ROM. El sentido último de una obra de referencia electrónica es la consulta y si sus mecanismos de búsqueda son inadecuados e ineficientes el esfuerzo se desperdicia.

Por su parte, la página de consulta en línea, elaborada por la DGACUNAM, parte del trabajo realizado por Viñas, al que actualiza y completa con datos provenientes de diversas fuentes secundarias. Contiene toda clase de producciones mexicanas, de realizadores mexicanos en el extranjero y de producciones extranjeras sobre México. También incluye una enorme cantidad de videobomes y de producciones en video que no 
distingue de las películas y son fuente de confusión para el usuario. Tampoco indica el formato de la película, sobre todo considerando que abarca la producción escolar del Centro de Capacitación Cinematográfica y del Centro Universitario de Estudios Cinematográficos. A diferencia de otros trabajos, este sí indica las fuentes de información de algunos de sus registros. La ficha incluye sinopsis y, ocasionalmente, citas textuales o la fuente de la información.

Básicamente, la Filmografía mexicana es un sistema de consulta. Como tal, su entrada principal es una caja de diálogo que permite ser interrogada por palabras sueltas. Una virtud del sistema es que permite realizar búsquedas libres por todos los campos de la base. Desafortunadamente, no puede hacer búsquedas complejas empleando la lógica booleana y la imposibilidad para recuperar información en más de un campo: buscamos en uno o en todos.

Más funcional que su contraparte en CD-ROM, la Filmografía mexicana de la Filmoteca de la UNAM debería contar con una presentación de su base de datos indicando alcance, número de registros, criterios de elaboración, fuentes, etcétera. Su sistema de búsqueda y recuperación debe incluir opciones "avanzadas". La ventaja de los documentos elaborados para la red de redes es la facilidad con la que pueden corregirse y actualizarse.

\section{Conclusiones}

Independiente del valor o validez de la información proporcionada por los trabajos filmogrficos reseñados arriba, ninguna de esas fuentes se ajusta a las normas internacionales para el registro de información documental.

A partir de las recomendaciones de la FIAF y de las propuestas para el control bibliográfico universal, consideramos que una filmografa nacional debe ser resultado de un trabajo colectivo, organizado y sistemático, que evite la dispersión del esfuerzo, la redundancia y la repetición. Las filmografías consignadas pecan de una sed de absoluto, intentan ser obras "definitivas" y "totales". Creemos que eso es imposible. El establecimiento de la filmografía mexicana será un trabajo permanente, de paulatino pero con creciente enriquecimiento. Sólo la coordinación y cooperación entre las diversos investigadores e instituciones permitirá la edición periódica de una filmografía fruto del trabajo colectivo y que sea confiable, crítica, normalizada y sistemática, en la que se conjunten, complementen y enriquezcan nuestros conocimientos sobre las películas mexicanas filmadas desde 1896 hasta el presente. 


\section{Bibliografia}

Fernando Martínez Ruiz y Ricardo Reynoso Serralde (coords.) (1999), Cien años de cine mexicano 1896-1996, CONACULTA/IMCINE/Universidad de Colima/ CENDIC, México.

1981-1982, El Cine Mexicano en Documentos, núms. 1-10.

CCF (1988), The Common Communication Format, Peter Simmons y Alan Hopkinson (eds.), 2a. ed., UNEsCO, Paris, Programa General de Informacion, Unisist, 196. p.

CCF (1992), The common communication format for bibliographic information, Peter Simmons y Alan Hopkinson (eds.), uNESCO, Paris, Programa General de Informacion, Unisist, $1963 \mathrm{p}$.

RUTV-CCCC (1993), Guía para la catalogación descriptiva de materiales audiovisuales, Red Universitaria de Televisión y Video, Comisión de Catalogación, Clasificación y Conservación, Dir. Gral de Bibliotecas, UNAM, México.

Dávalos Orozco, Federico (1989). Summa Filmica Mexicana : bacia una filmografía crítica del cine mudo mexicano (1916-1920), tesis, de licenciatura en sociología, UNAM, FCPS, México. 